\title{
Simulation of Hot-band Microstructure of C-Mn Steels during High Speed Cooling
}

\author{
M. THOMPSON, M. FERRY'1) and P. A. MANOHAR ${ }^{21}$ \\ Hot Rolling Group, BHP Integrated Steel, Port Kembla, NSW 2505 Australia. 11$)$ School of Materials Science and \\ Engineering University of New South Wales, Sydney, NSW 2052 Australia. E-mail: m.ferry@unsw.edu.au \\ 2) BHP Institute for Steel Processing and Products, University of Wollongong, Wollongong, NSW 2522 Australia.
}

(Received on February 15, 2000; accepted in final form on April 16, 2001)

\begin{abstract}
The evolution of microstructure in a range of $\mathrm{C}-\mathrm{Mn}$ steels during hot strip rolling and subsequent high speed cooling was simulated by quench dilatometry using cooling rates up to $600^{\circ} \mathrm{C} / \mathrm{s}$. The influence of coiling temperature on the microstructure and mechanical properties of the hot band was also investigated by interrupted cooling experiments. Continuous cooling transformation (CCT) diagrams for a range of cooling schedules were constructed for each steel where it was found that rapid cooling lowers significantly the $\mathrm{Ar}_{3}$ temperature, refines the ferrite to grain sizes in the range 3-6 $\mu \mathrm{m}$ and increases the hardness. An increase in $\mathrm{Mn}$ content (mass \%) from 0.45 to $1.0 \%$ lowers the $\mathrm{Ar}_{3}$ temperature, retards the rate of $\gamma \rightarrow \alpha$ transformation and promotes the formation of non-equilibrium phases. The role of alloying additions, in combination with cooling rate and coiling temperature is discussed in the context of microstructural development and strengthening of as-hot-rolled C-Mn strip.
\end{abstract}

KEY WORDS: dilatometry; CCT diagrams; C-Mn steel; accelerated cooling; hot strip mill.

\section{Introduction}

During hot rolling of steel, the final reductions are usually carried out in a series of finishing stands followed by controlled cooling to the desired coiling temperature. It is known that both cooling conditions on the run-out table and coiling temperature have a significant effect on the microstructural development of the as-hot-rolled steel strip. ${ }^{1,2)}$ These are useful methods for strengthening steel and allows the production of high strength steel strip without the need for substantial alloying. Furthermore, a lowering of the alloy content of the steel allows a reduction in the cost of producing strip and allows more ease of production. Accelerated cooling thus facilitates the development of high strength steel strip with lower carbon and manganese levels, which subsequently improves weldability. ${ }^{3)}$

In a typical hot strip mill (HSM), cooling rates of up to $120^{\circ} \mathrm{C} / \mathrm{s}$ are readily achievable on the run-out table by the use of a high intensity laminar flow cooling system. ${ }^{4)}$ This enables the control of microstructure, and hence, will produce the desired the yield and tensile strengths of hot rolled steel strip. Recent improvements in both cooling and control technology has allowed cooling rates up to $1000^{\circ} \mathrm{C} / \mathrm{s}$ to be achieved by water cooling systems in hot strip mills. ${ }^{5)}$ However, industrial trials are restricted by their expense and little systematic studies have been published on the effect of high speed cooling on the microstructure and properties of carbon steels. In particular, detailed information is required on the effect of rapid continuous cooling $\left(>100^{\circ} \mathrm{C} / \mathrm{s}\right) \mathrm{di}-$ rectly after hot rolling as well as the influence of interrupt- ed cooling (i.e. coiling) on the microstructural development and mechanical property control of $\mathrm{C}-\mathrm{Mn}$ steels. In this work, quench dilatometry was used to generate cooling rates of up to $600^{\circ} \mathrm{C} / \mathrm{s}$ in a range of $\mathrm{C}-\mathrm{Mn}$ steels in order to simulate controlled cooling of as-hot-rolled steel strip. The influence of $\mathrm{Mn}$ in low carbon steel, as well as continuous and interrupted high speed cooling on the rate and mode of austenite decomposition, and the resulting hardness were the focus of this investigation.

\section{Materials and Experimental Program}

Three grades of C-Mn steel, in the form of $6 \mathrm{~mm}$ hotrolled strip, were supplied by BHP Steel, Port Kembla. The chemical compositions of the steels are given in Table $\mathbf{1 .}$ The steels were prepared with the same general composition but with different concentrations of $\mathrm{Mn}$ ranging from 0.45 to 1.0 mass $\%$.

Samples were machined from as-hot-rolled strip to pro-

Table 1. Principal alloying elements (mass\%) and steel designation.

\begin{tabular}{|c|c|c|c|}
\hline Element & Fe-0.11C-0.45Mn & Fe-0.14C-0.74Mn & Fe-0.14C-1.0Mn \\
\hline \hline & $\mathbf{0 . 1 1}$ & $\mathbf{0 . 1 4}$ & $\mathbf{0 . 1 4}$ \\
$\mathbf{C}$ & $\mathbf{0 . 4 5}$ & $\mathbf{0 . 7 4}$ & $\mathbf{1 . 0}$ \\
Mn & 0.018 & 0.014 & 0.018 \\
$\mathrm{P}$ & 0.005 & 0.005 & 0.01 \\
$\mathrm{Si}$ & 0.022 & 0.024 & 0.02 \\
$\mathrm{Ni}$ & 0.02 & 0.014 & 0.015 \\
$\mathrm{Cr}$ & 0.038 & 0.032 & 0.03 \\
$\mathrm{Al}$ & & & \\
\hline
\end{tabular}


duce thin-walled cylinders of $4.5 \mathrm{~mm}$ external diameter, 3.5 $\mathrm{mm}$ internal diameter and length $10 \mathrm{~mm}$. All experiments were carried out in a vacuum $\left(10^{-4}\right.$ torr $)$ to limit possible decarburisation and/or oxidation of the samples during the heat treatment. The thermal cycle was controlled via a Type $\mathrm{S}$ thermocouple $(0.13 \mathrm{~mm}$ wire diameter) spot-welded on the surface of each sample. Cooling of the samples was obtained by controlling the flow of the high purity helium gas. The experimental program for dilatometry is presented schematically in Fig. 1. In a typical hot strip mill, the austenite grain size of $\mathrm{C}-\mathrm{Mn}$ steels after the final pass is

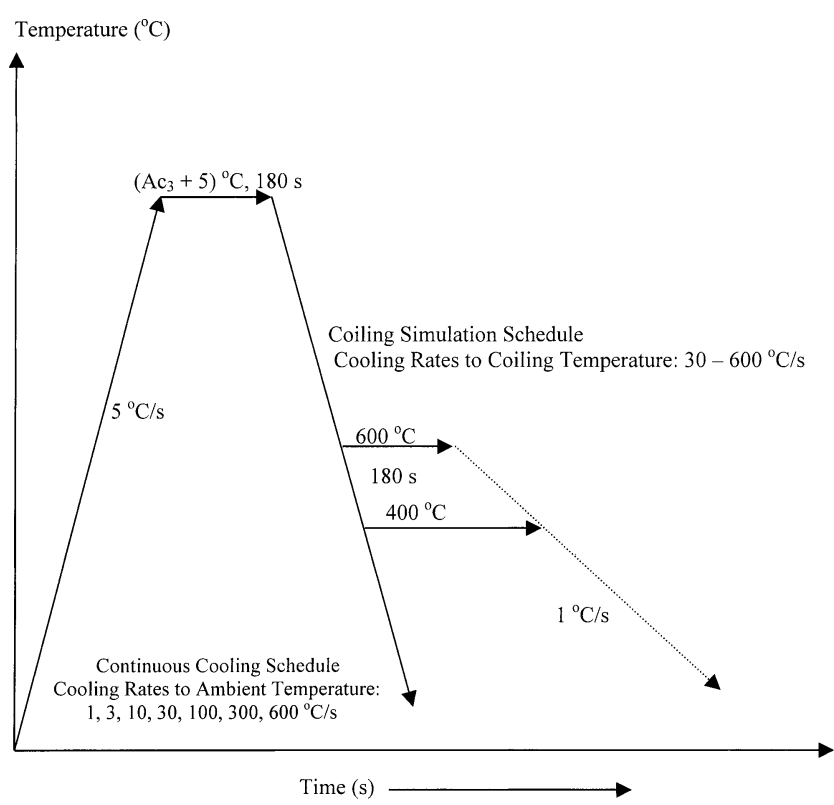

Fig. 1. Schematic diagram of experimental program for dilatometry. expected to be $10-12 \mu \mathrm{m}$. $\left.{ }^{6}\right)$ To simulate the microstructure after the final pass in a HSM, an austenite grain size $\sim 8 \mu \mathrm{m}$ was produced by heating each sample at a rate of $5^{\circ} \mathrm{C} / \mathrm{s}$ to a temperature of $5^{\circ} \mathrm{C}$ above $\mathrm{Ac}_{3}$ followed by soaking for $180 \mathrm{~s}$ to achieve a uniform sample temperature. The samples were subsequently cooled at a constant rate of 1 to $600^{\circ} \mathrm{C} / \mathrm{s}$ either to ambient temperature (continuous cooling schedule) or interrupted at a temperature of either $600^{\circ} \mathrm{C}$ or $400^{\circ} \mathrm{C}$ (coiling simulation schedule). The samples were held at the coiling temperature for $180 \mathrm{~s}$ before being cooled further to ambient temperature at $1{ }^{\circ} \mathrm{C} / \mathrm{s}$.

After thermal cycling, samples were sectioned and prepared for metallographic examination using conventional techniques. The microstructures were examined by both optical microscopy and scanning electron microscopy. For quantitative optical examination of the microstructure, dark-etching phases such as pearlite, bainite and martensite

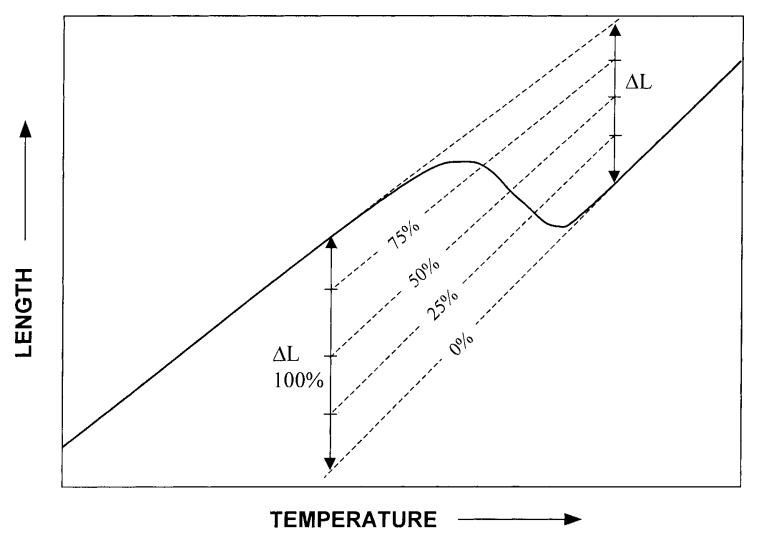

Fig. 2. Determination of the transformation temperature for a given percentage transformed.

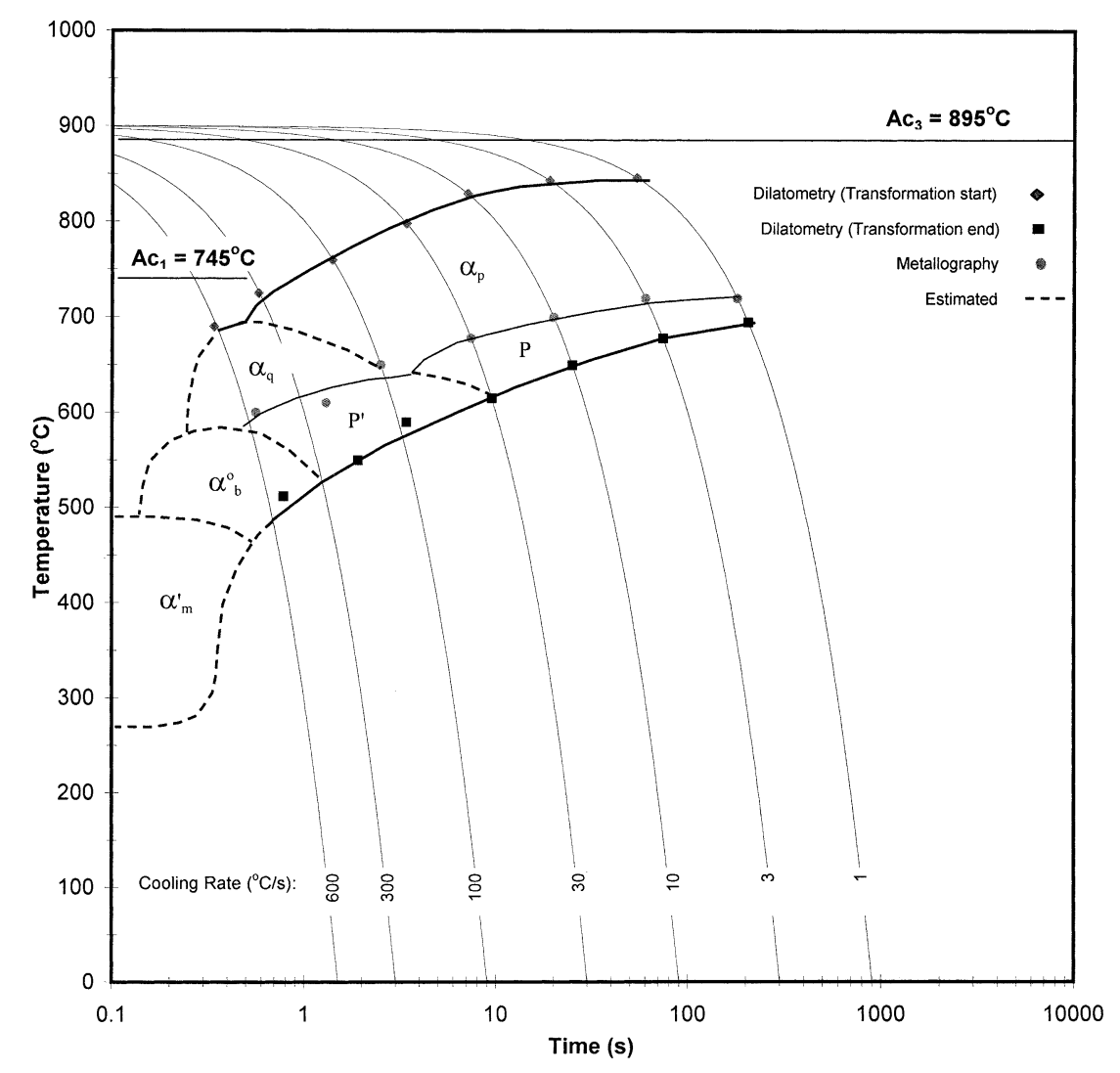

Fig. 3. CCT diagram for $\mathrm{Fe}-0.11 \mathrm{C}-0.45 \mathrm{Mn}$ steel. 
are referred to as non-equilibrium phases. Quantitative metallography was performed using image analysis where grain size measurements were based on mean linear intercept method. ${ }^{7)}$ Hardness measurements were made using Leco Vickers microhardness testing with a $200 \mathrm{~g}$ load. For a given cooling rate, the transformation start $\left(\mathrm{Ar}_{3}\right)$ and finish temperatures $\left(\mathrm{Ar}_{1}\right)$ were measured for each steel by locating the temperature at which the dilatation-temperature curve showed a $2 \%$ deviation from linearity (Fig. 2). CCT diagrams were then constructed using both data obtained from

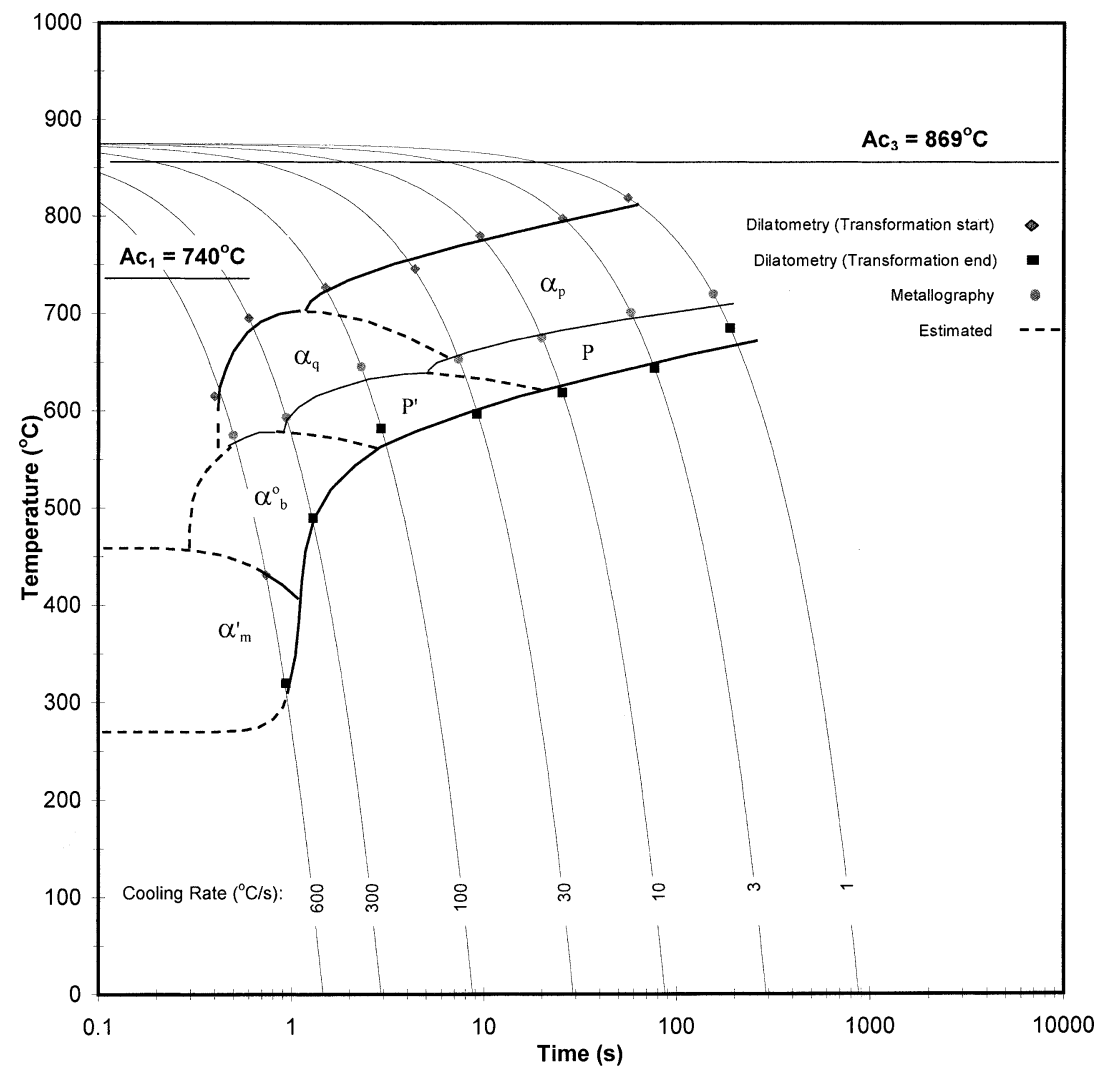

Fig. 4. CCT diagram for $\mathrm{Fe}-0.14 \mathrm{C}-0.74 \mathrm{Mn}$ steel.

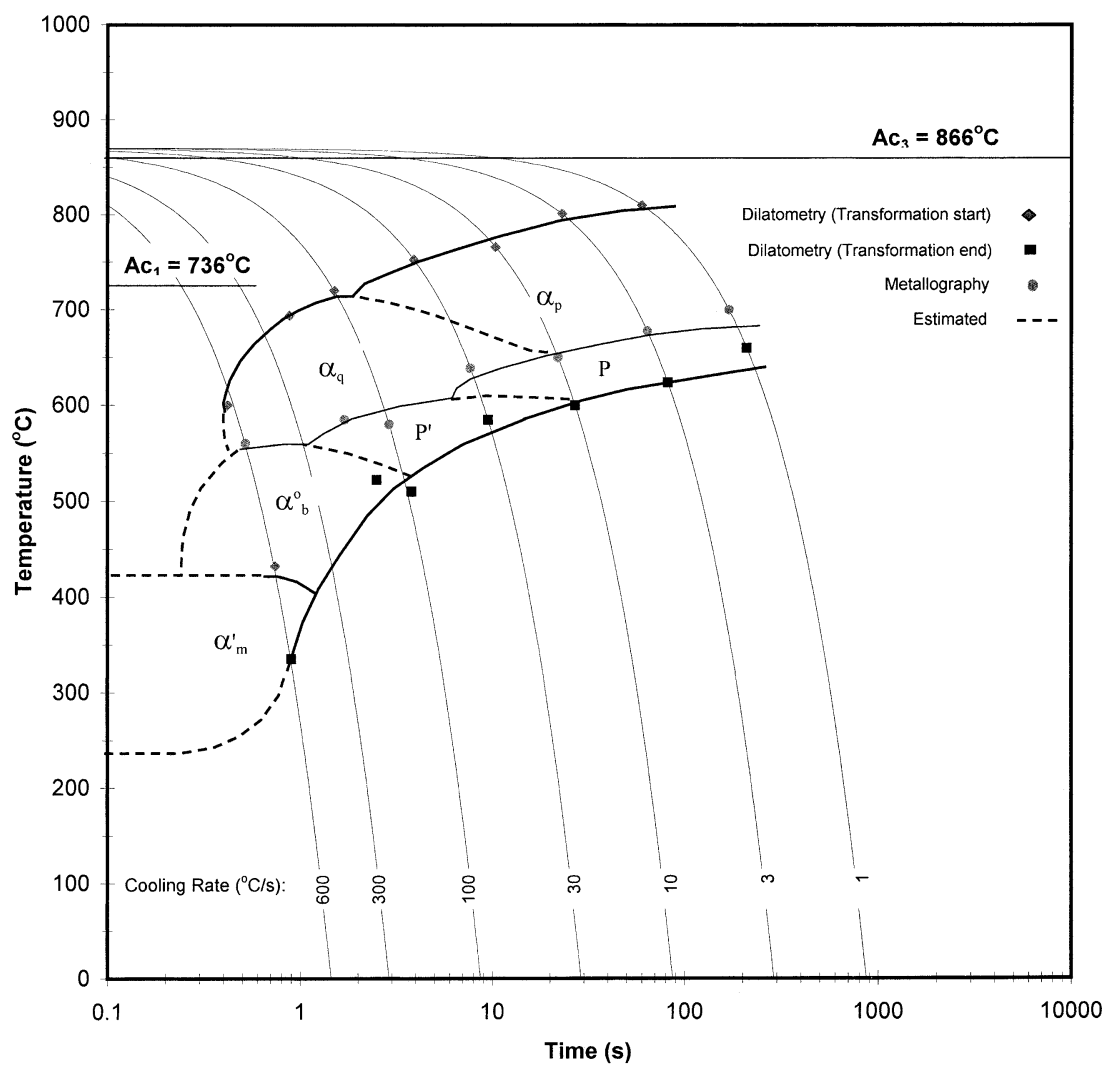

Fig. 5. CCT diagram for $\mathrm{Fe}-0.14 \mathrm{C}-1.0 \mathrm{Mn}$ steel. 
dilatometry and microstructural analysis. For C-Mn steels, it is expected that the transformed microstructure from austenite consists of different forms of ferrite and carbide aggregation, and so, quantitative metallography was used to locate the temperature of formation for each type of ferrite phase.

\section{Results}

\subsection{CCT Diagrams}

For the continuous cooling schedule, CCT diagrams for all steels are given in Figs. 3 to $\mathbf{5}$, with representative optical microstructures given in Fig. 6. Scanning electron mi- croscopy (SEM) was also used to identify the non-equilibrium transformation products and the phase nomenclature used here is based on the classification system proposed by ISIJ Bainite Committee. ${ }^{8,9)}$

A comparison of the CCT diagrams shows that an increase in both the $\mathrm{C}$ and Mn content shifts the ferrite transformation nose to slower cooling rates and lowers the CCT diagrams with respect to temperature. For example, the ferrite transformation nose for $\mathrm{Fe}-0.11 \mathrm{C}-0.45 \mathrm{Mn}$ is located beyond $300^{\circ} \mathrm{C} / \mathrm{s}$ (Fig. 3), while for $\mathrm{Fe}-0.14 \mathrm{C}-0.74 \mathrm{Mn}$ and $\mathrm{Fe}-0.14 \mathrm{C}-1.0 \mathrm{Mn}$, it is between $100-300^{\circ} \mathrm{C} / \mathrm{s}$ (Fig. 4) and $30-100^{\circ} \mathrm{C} / \mathrm{s}$ respectively (Fig. 5). An increase in $\mathrm{C}$ and $\mathrm{Mn}$ contents also causes the $\gamma \rightarrow \alpha$ transformation to occur over
Fe-0.11C-0.45Mn

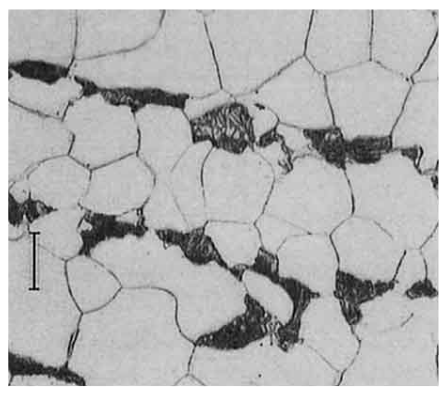

Cooling Rate: $1^{\circ} \mathrm{C} / \mathrm{s}$

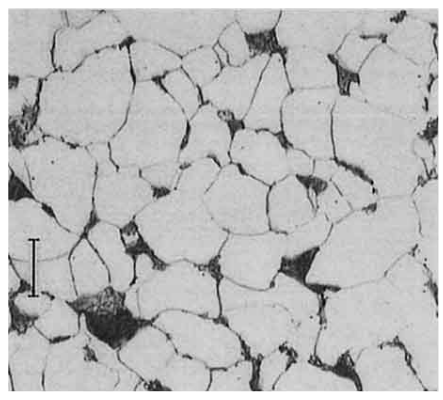

Cooling Rate: $10^{\circ} \mathrm{C} / \mathrm{s}$

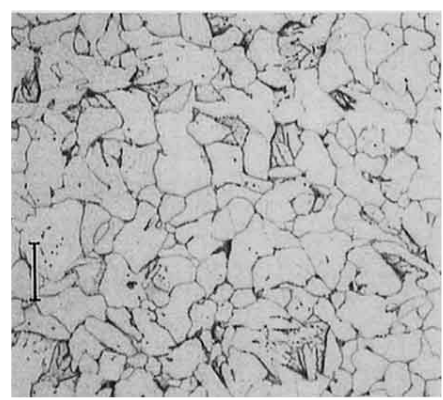

Cooling Rate: $100^{\circ} \mathrm{C} / \mathrm{s}$

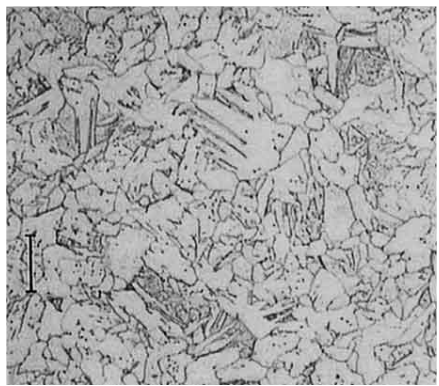

Cooling Rate: $600^{\circ} \mathrm{C} / \mathrm{s}$
Fe-0.14C-0.74Mn
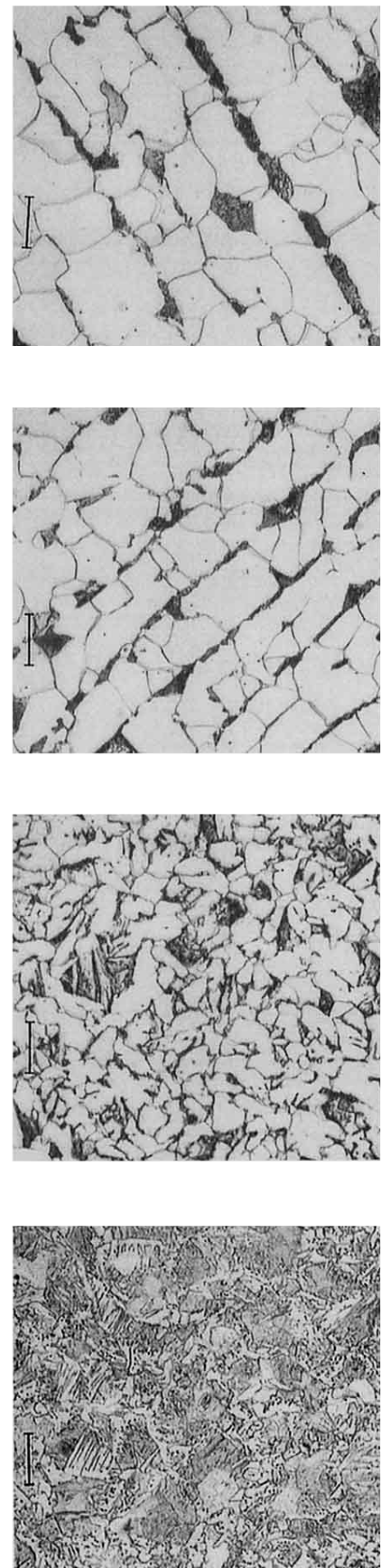

Fe-0.14C-1.0Mn
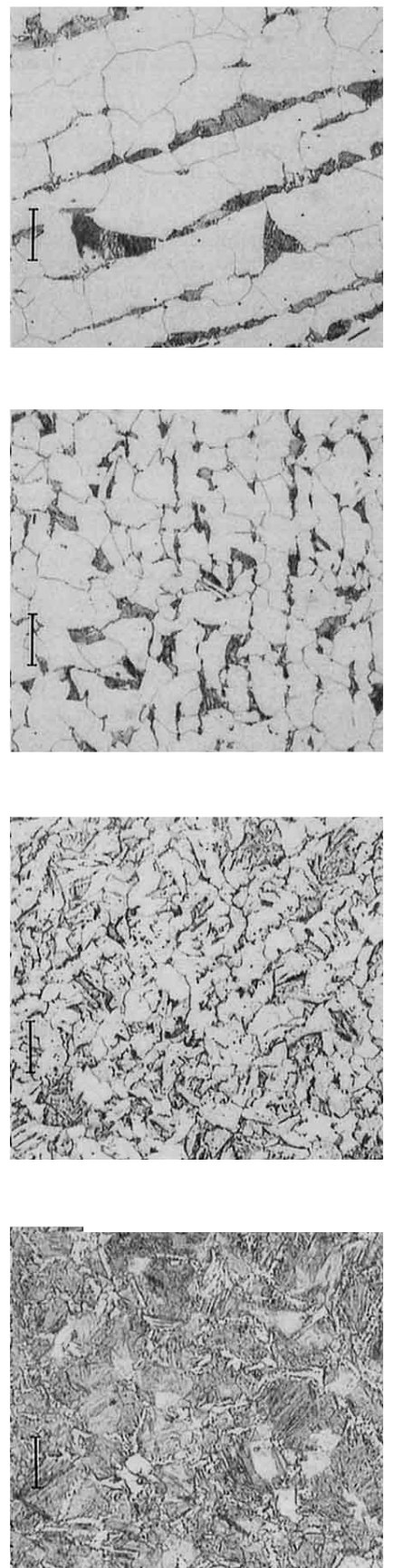

Fig. 6. Representative optical micrographs of steel samples continuously cooled to room temperature at the indicated cooling rates. $1000 \times$ magnification (scale bar represents $10 \mu \mathrm{m}$ ). Etchant: $2.5 \%$ Nital. 


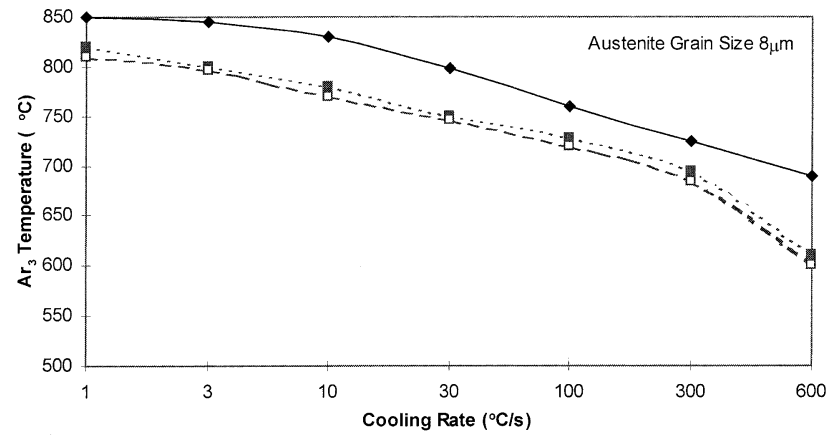

(a)

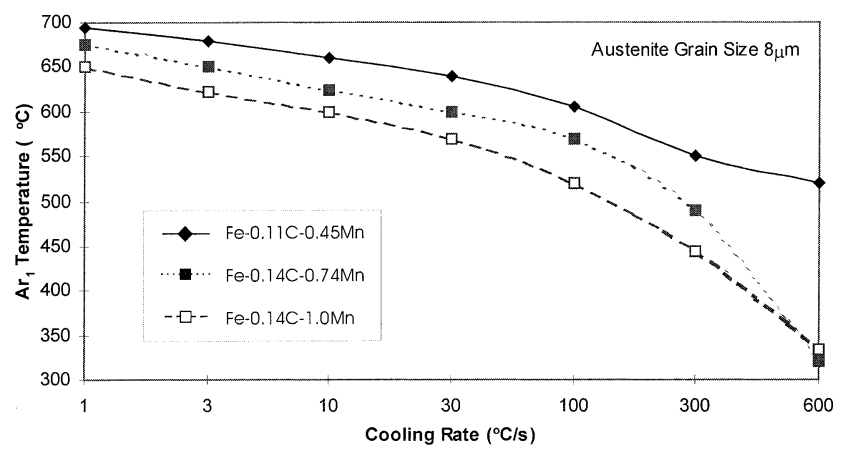

(b)

Fig. 7. Effect of cooling rate and steel composition on (a) $\mathrm{Ar}_{3}$ and (b) $\mathrm{Ar}_{1}$ temperatures.

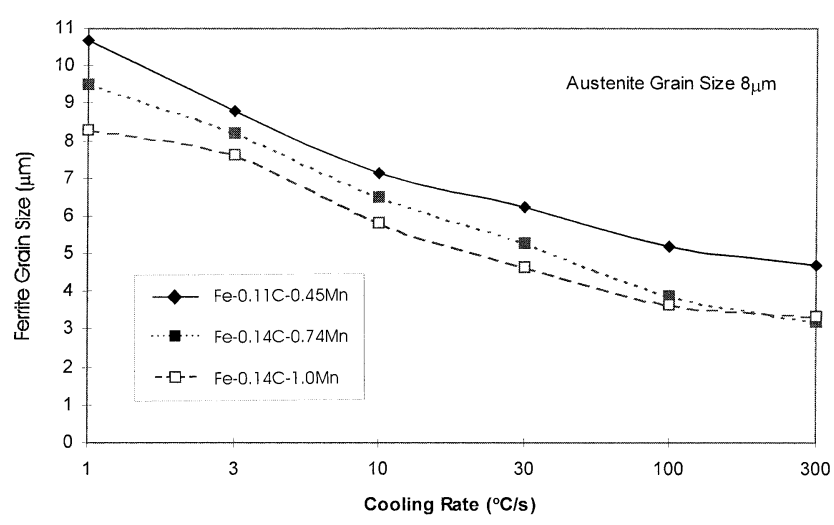

Fig. 8. Ferrite grain refinement as a function of cooling rate and steel composition.

a wider temperature range, which indicates slower transformation kinetics, that is, an increase in hardenability.

The influence of both cooling rate and composition on the $\mathrm{Ar}_{3}$ and $\mathrm{Ar}_{1}$ temperatures are shown in Figs. 7(a) and 7(b) respectively. An increase in cooling rate lowers both the $\mathrm{Ar}_{3}$ and $\mathrm{Ar}_{1}$ temperatures significantly and an increase in $\mathrm{C}-\mathrm{Mn}$ content lowers these temperatures to a lesser degree.

\subsection{Microstructural Development}

The development of microstructure as a function of cooling rate was found to be similar in all steels (Fig. 6). Taking the Fe-0.14C-1.0Mn steel as an example, Fig. 6 shows the change in microstructure of the second phase from lamellar pearlite at cooling rates of $1-30^{\circ} \mathrm{C} / \mathrm{s}$ to a mixture of degenerated pearlite and fine lamellar pearlite at rates of $30-300^{\circ} \mathrm{C} / \mathrm{s}$, and finally at cooling rates greater than $300^{\circ} \mathrm{C} / \mathrm{s}$, a mixture of lathlike bainite/martensite is pro-

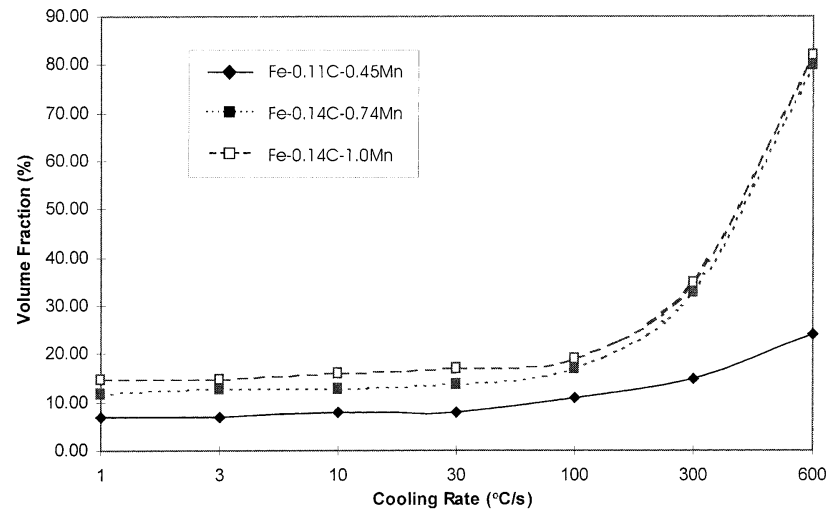

Fig. 9. Effect of cooling rate and steel composition on the volume fraction of non-equilibrium phases.

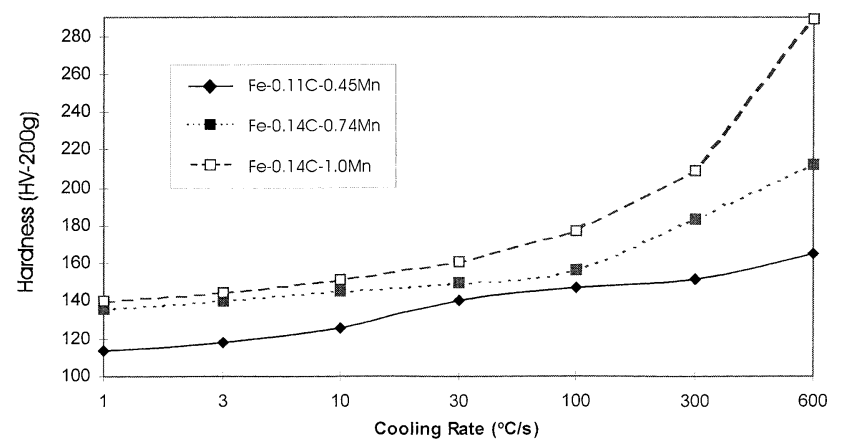

Fig. 10. Effect of cooling rate and steel composition on the hardness of transformation products.

duced (with or without interlath carbides). For all steels, microstructural banding was found to disappear at cooling rates of $10-30^{\circ} \mathrm{C} / \mathrm{s}$.

As shown in Fig. 8, accelerated cooling of C-Mn steels resulted in significant grain refinement of ferrite with final grain sizes below $5 \mu \mathrm{m}$ produced at $600^{\circ} \mathrm{C} / \mathrm{s}$. An increase in alloying content also refines the ferrite grain size to some extent. The volume fraction of non-equilibrium phase as a function of cooling rate and composition is given in Fig. 9 where it can be seen that non-equilibrium phase increases gradually following cooling at rates up to $100^{\circ} \mathrm{C} / \mathrm{s}$ with a sharp increase at higher cooling rates. An increase in C-Mn also produces, for a given cooling rate, a higher content of non-equilibrium phase. The combination of ferrite grain refinement and this increase in volume fraction of non-equilibrium phase results in a significant increase in hardness as shown in Fig. 10.

\subsection{Effect of Coiling Temperature on Microstructural Modification}

As a representative example, the development of microstructure in the $\mathrm{Fe}-0.14 \mathrm{C}-0.74 \mathrm{Mn}$ steel as a function of initial cooling rate and coiling temperature is shown in Fig. 11. Compared with continuous cooling (Fig. 6), the microstructures produced following coiling at a temperature below $\operatorname{Ar}_{1}$ (i.e. $400^{\circ} \mathrm{C}$ ) exhibited a slightly greater amount of coarse polygonal ferrite. Conversely, the microstructures produced following holding at $600^{\circ} \mathrm{C}$, for a given cooling rate, consisted of coarser polygonal ferrite and degenerate pearlite. The influence of coiling temperature on hardness for all steels is shown in Fig. 12. It is apparent from Fig. 12 
$600^{\circ} \mathrm{C}$ Simulated Coiling Temperature

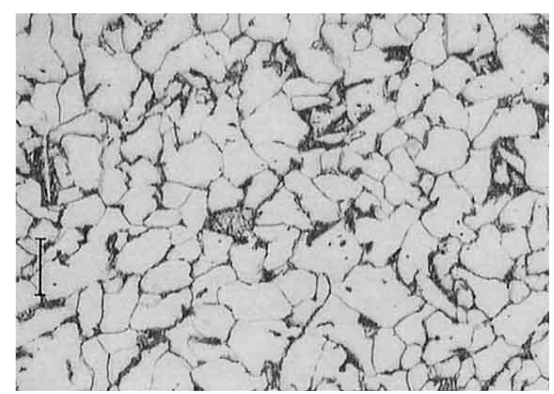

$30^{\circ} \mathrm{C} / \mathrm{s}$

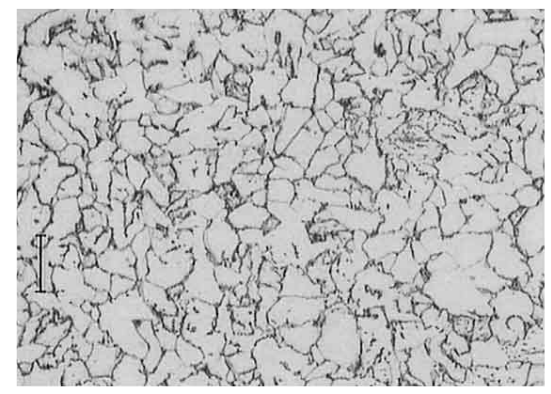

$100^{\circ} \mathrm{C} / \mathrm{s}$

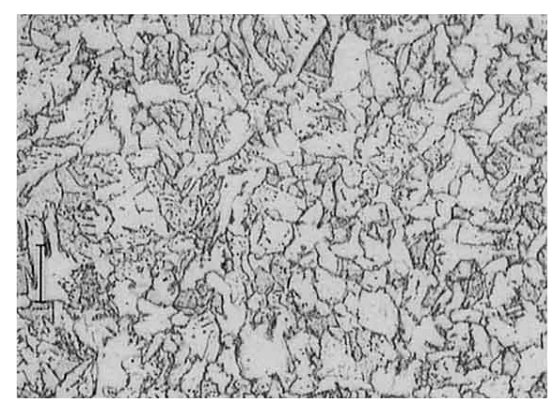

$300^{\circ} \mathrm{C} / \mathrm{s}$

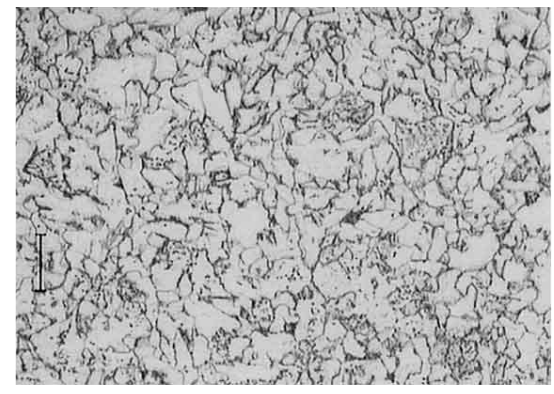

$600^{\circ} \mathrm{C} / \mathrm{s}$ $400^{\circ} \mathrm{C}$ Simulated Coiling Temperature

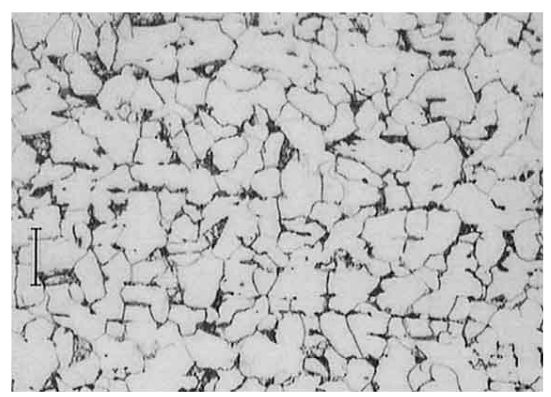

$30^{\circ} \mathrm{C} / \mathrm{s}$

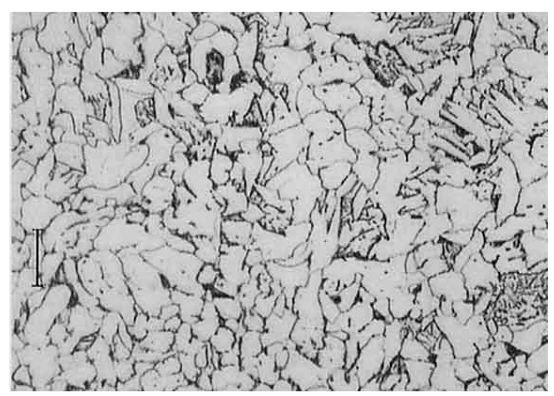

$100^{\circ} \mathrm{C} / \mathrm{s}$

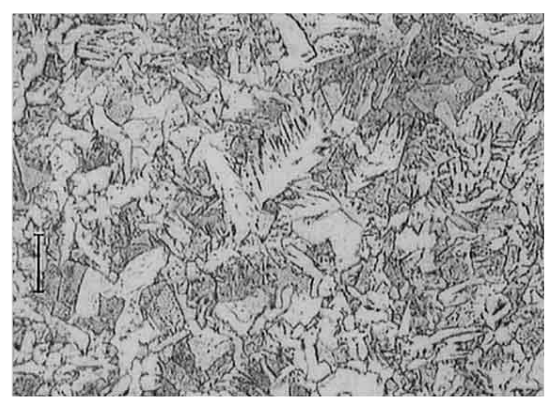

$300^{\circ} \mathrm{C} / \mathrm{s}$

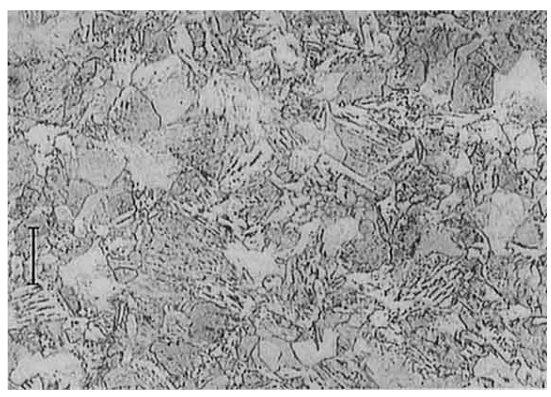

$600^{\circ} \mathrm{C} / \mathrm{s}$

Fig. 11. Representative optical micrographs of $\mathrm{Fe}-0.14 \mathrm{C}-0.74 \mathrm{Mn}$ steel samples cooled at the indicated rates to the simulated coiling temperature of 600 and $400^{\circ} \mathrm{C} .1000 \times$ magnification (scale bar represents $10 \mu \mathrm{m}$ ). Etchant: $2.5 \%$ Nital.

that, for a given steel composition and at cooling rates greater than $100^{\circ} \mathrm{C} / \mathrm{s}$, coiling at $600^{\circ} \mathrm{C}$ produces a microstructure with a lower hardness compared with those produced both after coiling at $400^{\circ} \mathrm{C}$ and continuous cooling. Furthermore, hardness is essentially independent of cooling rate for the high coiling temperature.

\section{Discussion}

\subsection{Kinetics of Austenite Decomposition}

Manganese in steel is an austenite stabiliser and hence affects its rate of decomposition. It has been reported that an increase in Mn content results in a decrease in the ferrite growth rate it affects the thermodynamic stability of austenite relative to ferrite. ${ }^{10)}$ Similar to previous work on microalloyed steels, ${ }^{11,12)}$ increasing the Mn content retards both the onset (lowers $\mathrm{Ar}_{3}$ ) and progress (lowers $\mathrm{Ar}_{1}$ ) of transformation in the C-Mn steel (Figs. 7(a) and 7(b)). The retarding effect of $\mathrm{Mn}$ on the rate of decomposition of austenite has been attributed to segregation of $\mathrm{Mn}$ atoms along the $\alpha / \gamma$ phase boundary causing a strong solute drag effect. ${ }^{13,14)}$ The addition of Mn to steel also decreases the activity of $\mathrm{C}$ in austenite ${ }^{15)}$ thereby promoting the formation of non-equilibrium phases, such as degenerate pearlite and MA (martensite-austenite island) constituents in preference to lamellar pearlite. 

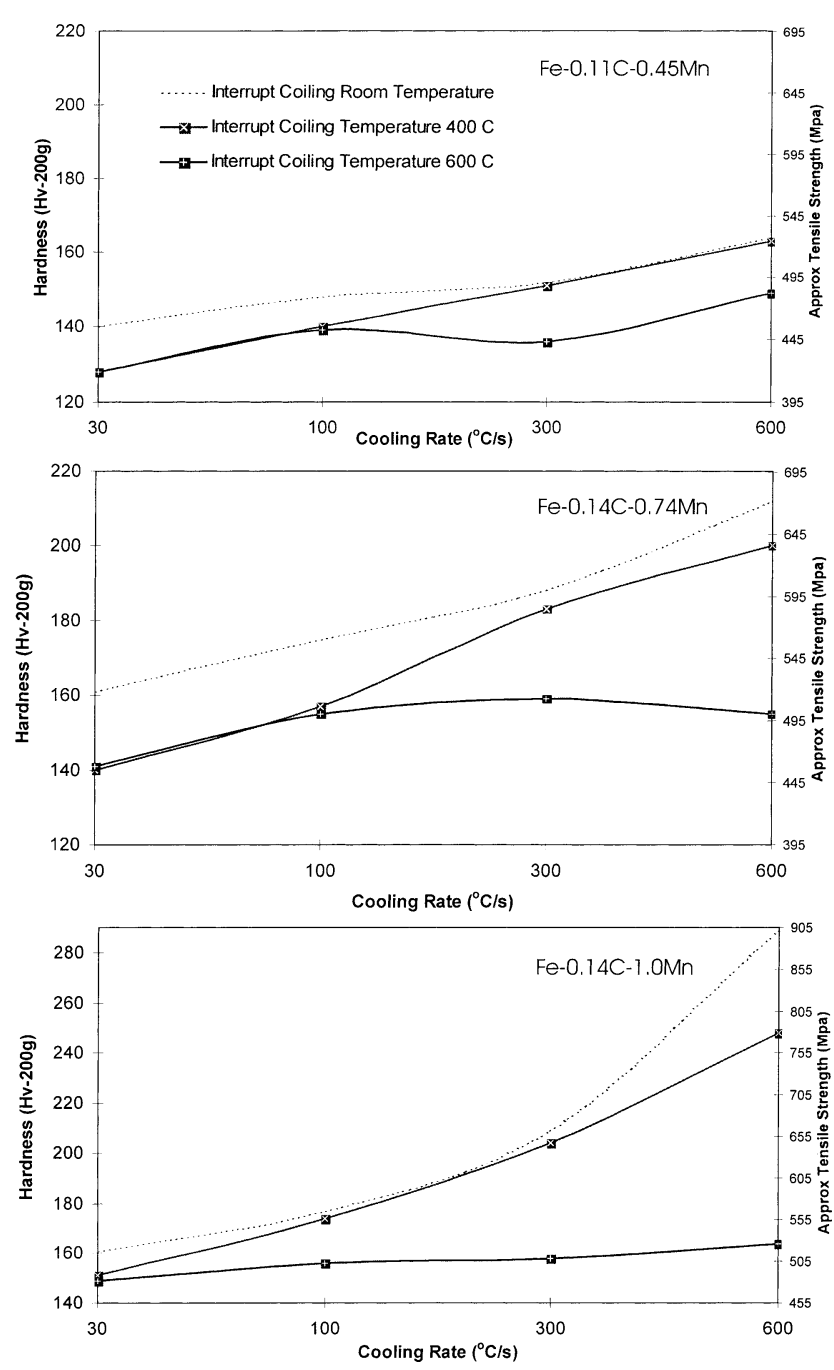

Fig. 12. Influence of cooling rate and coiling temperature on the average hardness and estimated strength of the steels studied.

The effect of cooling rate on ferrite grain refinement was illustrated in Fig. 8 and this can be explained as follows: As the cooling rate is increased, the temperature at which the first nuclei form $\left(\mathrm{Ar}_{3}\right)$ is lowered. This causes a corresponding increase in the undercooling $\left(\Delta T=\mathrm{Ae}_{3}-\mathrm{Ar}_{3}\right)$, which results in an increased nucleation rate at both ferrite grain boundaries and grain interiors. Due to the enhanced nucleation density at high cooling rates, grain growth is restricted by mutual impingement, which results in a finer ferrite grain size.

\subsection{Microstructural Banding}

At low cooling rates, the microstructure of all steels consisted of banded ferrite and pearlite but higher cooling rates suppressed its formation. The critical cooling rate required to completely suppress banding was dependent on carbon content of the steel and ranged from $3-10^{\circ} \mathrm{C} / \mathrm{s}$ for $\mathrm{Fe}-$ $0.11 \mathrm{C}-0.45 \mathrm{Mn}$ to $10-30^{\circ} \mathrm{C} / \mathrm{s}$ for both $\mathrm{Fe}-0.14 \mathrm{C}-0.74 \mathrm{Mn}$ and $\mathrm{Fe}-0.14 \mathrm{C}-1.0 \mathrm{Mn}$. Banding is a result of interdendritic segregation of substitutional elements such as Mn during solidification whereby, during hot rolling, these Mn-rich zones spread out into sheets to generate alternating layers of Mn-rich and Mn-lean regions. On subsequent cooling after hot rolling, Mn-lean regions may transform to ferrite that causes carbon diffusion out of these regions, and acts to depress the transformation temperature ahead of the $\gamma / \alpha$ interface. If the cooling rate is low, this process repeats and carbon diffuses to the Mn-rich regions, which will promote the transformation of the remaining austenite to pearlite. ${ }^{16)}$ During accelerated cooling, however, the rate of ferrite nucleation is increased and carbon has insufficient time to diffuse to Mn-rich regions thereby favouring a more uniform eutectoid reaction which results in local disappearance of the banded ferrite-pearlite structure. It has also been suggested $^{16)}$ that accelerated cooling causes ferrite nucleation to become more homogenous, that is, ferrite nucleation occurs both in the Mn lean and rich regions leading to a more uniform distribution of ferrite and pearlite in the microstructure.

\subsection{Coiling Simulation}

It is known that the final microstructure and hardness of plain C-Mn steels is dependent on the cooling rate through the austenite transformation temperature range as well as coiling temperature. ${ }^{4)}$ Strengthening in these steels is generally attributed to a combination of ferrite grain refinement, the increase in volume fraction (and change in morphology) of non-equilibrium transformation products, and strengthening of ferrite itself. ${ }^{10)}$ The combination of ferrite grain refinement and the increase in volume fraction of non-equilibrium phase have been used to explain the strength increase associated with accelerated cooling of steel strip. However, it has been recently shown ${ }^{6}$ that these mechanisms are dependent only on the cooling rate if the coiling temperature is below the final austenite transformation temperature. The present work supports this view where it is found that accelerated cooling has little influence on strengthening if the coiling temperature is considerably higher than $\mathrm{Ar}_{1}$. This behaviour may be explained by the order of the decomposition reactions. For a given steel, nucleation and growth of ferrite precedes the formation of non-equilibrium phases and when the transformation is interrupted at high temperature $\left(600^{\circ} \mathrm{C}\right)$, ferrite is already produced with the secondary products forming isothermally. Therefore, despite the rate of initial cooling, high temperature coiling will produce similar microstructures and hardness of the non-equilibrium constituents. Clearly, the mechanical properties of a given steel can be vastly improved by accelerated cooling only when the coiling temperature is set below the finish transformation temperature.

Table 2 shows a very close comparison of microstructures and hardness of samples produced by laboratory simulation with those obtained by industrial processing. ${ }^{17)}$ These results confirm that laboratory simulation is a rapid and inexpensive means for accurately predicting the microstructures and properties of steels after hot rolling and high-speed cooling. The results also predict, for the more highly alloyed plain $\mathrm{C}-\mathrm{Mn}$ steel, that high-speed cooling $\left(>300^{\circ} \mathrm{C} / \mathrm{s}\right)$ together with a low coiling temperature $\left(400^{\circ} \mathrm{C}\right)$ produces estimated tensile strengths in excess of $650 \mathrm{MPa}$ in as-hot-rolled strip (Fig. 12). Therefore, the control of steel composition and processing variables such as cooling rate and coiling temperature after hot rolling, allows the production of low carbon steel plate and strip products with improved mechanical properties. 
Table 2. Comparison between microstructure and mechanical properties of the steels produced by laboratory simulation and data from the BHP hot strip mill.

\begin{tabular}{|c|c|c|c|}
\hline Alloy & HSM * & \multicolumn{2}{|c|}{ Quench Dilatometry } \\
\hline \multicolumn{4}{|l|}{ Fe-0.11C-0.45Mn } \\
\hline Cooling Rate $\left({ }^{\circ} \mathrm{C} / \mathrm{s}\right)$ & $20-30$ & 30 & 30 \\
\hline Coiling Temperature $\left({ }^{\circ} \mathrm{C}\right)$ & $620 \pm 30$ & 600 & 400 \\
\hline Matrix Phase & $\alpha_{p}$ & $\alpha_{\mathrm{p}}$ & $\alpha_{p}$ \\
\hline Non-equilibrium Phase & $P$ & $P$ & $\mathrm{P}$ \\
\hline Grain Size $(\mu \mathrm{m})$ & 7.1 & 6.3 & 6.3 \\
\hline Non-equilibrium Phase (\%) & 8 & 8 & 8 \\
\hline Vickers Hardness & 124 & 129 & 128 \\
\hline \multicolumn{4}{|l|}{$\mathrm{Fe}-0.14 \mathrm{C}-0.74 \mathrm{Mn}$} \\
\hline Cooling Rate $\left({ }^{\circ} \mathrm{C} / \mathrm{s}\right)$ & $50-60$ & 30 & 100 \\
\hline Coiling Temperature $\left({ }^{\circ} \mathrm{C}\right)$ & $460 \pm 30$ & 400 & 400 \\
\hline Matrix Phase & $\alpha_{\mathrm{p}} \& \alpha_{\mathrm{Q}}$ & $\alpha_{p}$ & $\alpha_{p} \& \alpha_{Q}$ \\
\hline Non-equilibrium Phase & P \& P' & $P$ & P\& P' \\
\hline Grain Size $(\mu \mathrm{m})$ & 4.8 & 5.4 & 3.9 \\
\hline Non-equilibrium Phase (\%) & 14 & 14 & 17 \\
\hline Vickers Hardness & 150 & 140 & 157 \\
\hline \multicolumn{4}{|l|}{$\mathrm{Fe}-0.14 \mathrm{C}-1.0 \mathrm{Mn}$} \\
\hline Cooling Rate $\left({ }^{\circ} \mathrm{C} / \mathrm{s}\right)$ & $100-110$ & 100 & 300 \\
\hline Coiling Temperature $\left({ }^{\circ} \mathrm{C}\right)$ & $460 \pm 30$ & 400 & 400 \\
\hline Matrix Phase & $\alpha_{0}$ & $\alpha_{Q}$ & $\alpha_{0}$ \\
\hline Non-equilibrium Phase & $P^{\prime} \& \alpha^{0}{ }_{B}$ & $P^{\prime} \& \alpha_{B}^{0}$ & $\mathrm{P}^{\prime} \& \alpha_{\mathrm{B}}^{0}$ \\
\hline Grain Size $(\mu \mathrm{m})$ & 3.5 & 3.7 & 3.4 \\
\hline Non-equilibrium Phase (\%) & 33 & 20 & 36 \\
\hline Vickers Hardness & 180 & 174 & 204 \\
\hline
\end{tabular}

* Data taken from rolling trials carried out in the hot strip mill at BHP Steel, Port Kembla, Australia (Ref. [17]).

\section{Conclusions}

Experiments using quench dilatometry were conducted to simulate high-speed cooling on the run-out table and coiling simulations for a hot strip mill. The results of the simulation have shown that:

- For a given steel, accelerated, continuous cooling results in a significant ferrite grain refinement, increase in hardness, together with the development of non-equilibrium phases such as quasi-polygonal ferrite, degenerate pearlite and acicular bainite.

- An increase in Mn content retards the rate of transformation to ferrite and causes significant increase in hardness associated with an increase in volume fraction of non-equilibrium transformation products along with ferrite grain refinement.

- Interrupted cooling at a temperature above $\mathrm{Ar}_{1}$ has little influence on microstructure and hardness for a wide range of cooling rates $\left(30\right.$ to $\left.600^{\circ} \mathrm{C} / \mathrm{s}\right)$. In contrast, interrupted cooling at a temperature below $\mathrm{Ar}_{1}$ results in a marked increase in hardness.

\section{Acknowledgments}

The authors wish to thank BHP Steel for supplying the steels. The authors are grateful to Mr Paul Kelly (BHP) for fruitful discussions and Prof. B. A. Parker, Faculty of Engineering, University of Wollongong for the provision of laboratory facilities during the course of the experimental program.

\section{REFERENCES}

1) H. de Boer, H. Beenken, P. Branscheid, F-J Flobdorf, W. Haumann, W. Hof and H. Litzke: Proc. Int. Conf. on HSLA Steels: Metallurgy and Applications, ed. by J. M. Gray et al., Chinese Society of Metals, Beijing, (1985), 539.

2) M. Umemoto, Z. H. Guo and I. Tamura: Mater. Sci. Technol., 3 (1987), 249.

3) O. Grong and D. K. Matlock: Int. Met. Rev., 31 (1986), 27.

4) P. G. Kelly, A. Cabello, P. D. Edwards, P. M. Draper and J. G. Williams: Proc. Biennial Materials Conf. Materials '98, ed. by M. Ferry, Wollongong University Press, Wollongong, (1998), 203.

5) P. Simon, J. P. Fischbach and Ph. Riche: La Revue de Metallurgie CIT, 93 (1996), 410.

6) B. Debray, P. Teracher and J. J. Jonas: Metall. Mater. Trans. A, 26 (1995), 99.

7) ASTM E 112-96, Annual Book of ASTM Standards, 03.01 (1997), 227.

8) T. Araki and K. Shibata: Proc. Int. Conf. on HSLA Steels '95, ed. by L. Guoxun et al., Chinese Society of Metals, Beijing, (1995), 13.

9) T. Araki, M. Enomoto and K. Shibata: Mater. Trans. JIM, 32 (1991), 729.

10) R. W. K. Honeycombe and H. K. D. H. Bhadeshia: SteelsMicrostructures and Properties, 2nd ed., Edward Arnold, London, (1995), 68.

11) P. A. Manohar and T. Chandra: ISIJ Int., 38 (1998), 766.

12) P. A. Manohar and T. Chandra: Proc. Int. Conf. Thermec '97, ed. by T. Chandra and T. Sakai, TMS, Warrendale, PA, (1997), 749.

13) S. K. Liu and G. Y. Zhang: Metall. Trans. A, 21 (1990), 1509.

14) S. K. Liu and J. Zhang: Metall. Trans. A, 21 (1990), 1517. 
ISIJ International, Vol. 41 (2001), No. 8

15) J. S. Kirkaldy, B. A. Thomson and E. A. Baganis: Proc. Int. Symp. Hardenability Concepts with Applications to Steel, ed. by D. V. Doane and J. S. Kirkaldy, Warrendale, PA, AIME, New York, (1978), 82 .
16) C-T Wu and Y-T Pan: Proc. Int. Symp. on Processing, Microstructure and Properties of HSLA Steels, ed. by A. J. DeArdo, Jr., TMS, Warrendale, PA, (1988), 345.

17) M. Thompson: BEng Thesis, University of Wollongong, (1999). 